\title{
Synthesis, absorption spectra and semiempiric calculations on the photochromism of arylmercuric dithizonate complexes
}

\author{
T. Schönherr,,${ }^{1,3, \dagger}$ V. Schmid, ${ }^{1}$ R. Linder, ${ }^{1}$ M. F. R. Fouda, ${ }^{2}$ \\ R. S. Amin, ${ }^{2}$ and S. A. Mostafa ${ }^{2}$ \\ ${ }^{1}$ Heinrich-Heine-Universität, Institut für Theoretische Chemie, Düsseldorf, Germany \\ ${ }^{2}$ National Research Center, Inorganic Chemistry Department, Cairo, Egypt \\ ${ }^{3}$ Institut für Theoretische Chemie, Heinrich-Heine-Universität, Universitätstrasse 1, \\ D - 40225 Düsseldorf, Germany
}

\begin{abstract}
A series of arylmercuric dithizonate complexes have been synthesized and characterized. Optical spectra of dissolved and pure compounds show transition energies around $480 \mathrm{~nm}$ which have been rationalized by semiempiric PM3 calculations. All complexes show a pronounced photochromism. The calculations also account for the observed blue absorption of the metastable species when an underlying geometric arrangement according to the proposal of Meriwether's is assumed.
\end{abstract}

\section{INTRODUCTION}

The exploration of the photochromic behavior that occurs in solutions of several dithizone complexes [1] is an exciting challenge for theoreticians and experimentalists. The dithizone itself (abbr. here as $\mathrm{H}_{2} \mathrm{Dz}$ ) was introduced in analytical chemistry more than 60 years ago. However, the nature of excited electronic states as well as the underlying molecular structure is still controversially discussed. While the traditional view expects for dissolved dithizone a tautomeric equilibrium between the keto form (a) $(\mathrm{Ph}-\mathrm{NH}-\mathrm{NH}-\mathrm{CS}-\mathrm{N}=\mathrm{N}-\mathrm{Ph})$ and the enol form (b) $(\mathrm{Ph}-\mathrm{NH}-\mathrm{N}=\mathrm{C}(\mathrm{SH})-\mathrm{N}=\mathrm{N}-\mathrm{Ph})[1]$, Hutton [2] and Fabian [3] have found arguments also for the appearance of the symmetrical $\left(\mathrm{C}_{2 \mathrm{v}}\right)$ form (c) $(\mathrm{Ph}-\mathrm{NH}-\mathrm{N}-\mathrm{CS}-\mathrm{N}-\mathrm{NH}-\mathrm{Ph})$. In a recent theoretical investigation we have addressed the question of stability and molecular geometry to the variety of possible conformers of the three tautomeric forms and have compared the calculations with new findings from low-temperature optical and high-resolution (500 MHz) NMR experiments $[4,5]$. This has led to the conclusion that an equilibrium between forms (b) and (c) is present in solution, while form (a) seems not to exist at all [4-7]. However, for the present investigation on the photochromism of dithizone complexes another finding is much more important. It concerns the ability of the PM3 method to account for the optical spectrum (singlet transitions) of solid and dissolved dithizone $[5,7]$. The complicated electronic structure of this molecule demands for an advanced theoretical treatment which is given with parameter-free ab initio techniques or density functional calculations. However, despite of the enormous progress reached in computer hardware and quantum chemical treatments in the last

†E-mail: ts@theochem.uni-duesseldorf.de decade, the exploration of larger molecules is still the domain of semiempiric methods. This is particularly true for primary $(1: 2)$ and secondary $(1: 1)$ dithizone complexes, where about 40 to 70 atoms have to be considered explicitly. The promising results we have obtained when describing structural and optical properties of the dithizone molecule by means of PM3 calculations encouraged us to start such an investigation also on metal dithizonate complexes which show the phenomenon of photochromism. As outlined in detail elsewhere [7, 8],the proposal of Meriwether et al., who postulated that the photochromic transformation of mercury(II) bisdithizonate involves a trans-cis isomerization about the $\mathrm{C}-\mathrm{N}$ bond and $\mathrm{N}-\mathrm{to}^{-} \mathrm{N}$ hydrogen transfer [9], could be confirmed by calculation of optimized geometries and singlet-singlet transitions within the framework of the PM3 method. The continuous interest in $\mathrm{Hg}(\mathrm{HDz})_{2}$ is due to the reversibility of the yellow-blue photoisomerism and to the outstanding long lifetime, which can exceed a minute in dependence of the solvent. While photochromism has been observed also for many other heavy metal complexes with the dithizone ligand, the rates of the thermal return reactions are usually too fast for conventional measurements or, particularly, in view of possible technical applications. In this article we describe the synthesis and optical properties of some arylmercuric dithizonates, which show, otherwise, long-living metastable excited states in solution at room temperature.

\section{MATERIALS AND METHODS}

2.1. SYNTHESIS. Preparation of arylmercuric compounds. The synthetic procedure, which is similar to Irving's work [10], used a particular method described below in order to achieve very pure compounds. Starting materials for the preparation of complexes are 
Table 1. Characterization of starting materials ArHgCl(arylmercuric compounds).

\begin{tabular}{|c|c|c|c|c|c|}
\hline No & $\mathrm{Ar}$ & Empirical formula & $\begin{array}{c}\text { Analysis } \\
\text { Calc. }\end{array}$ & $\begin{array}{l}(\mathrm{Hg} \%) \\
\text { Found }\end{array}$ & $\begin{array}{c}\text { Thermal } \\
\text { Decomposition* }\end{array}$ \\
\hline 1 & $\mathrm{C}_{6} \mathrm{H}_{5}$ & $\mathrm{C}_{6} \mathrm{H}_{5} \mathrm{ClHg}$ & 64.05 & 64.20 & $216-259$ \\
\hline 2 & $o-\mathrm{OH} . \mathrm{C}_{6} \mathrm{H}_{4}$ & $\mathrm{C}_{6} \mathrm{H}_{5} \mathrm{ClHgO}$ & 60.94 & 60.60 & $140-183$ \\
\hline 3 & $p$-OH.C ${ }_{6} \mathrm{H}_{4}$ & $\mathrm{C}_{6} \mathrm{H}_{5} \mathrm{ClHgO}$ & 60.94 & 60.40 & $200-227$ \\
\hline 4 & $o-\mathrm{CH}_{2} \mathrm{OH} . \mathrm{C}_{6} \mathrm{H}_{4}$ & $\mathrm{C}_{7} \mathrm{H}_{7} \mathrm{ClHgO}$ & 58.45 & 58.70 & $229-265$ \\
\hline 5 & $p-\mathrm{CH}_{2} \mathrm{OH} . \mathrm{C}_{6} \mathrm{H}_{4}$ & $\mathrm{C}_{7} \mathrm{H}_{7} \mathrm{ClHgO}$ & 58.45 & 58.50 & $230-274$ \\
\hline 6 & $o-\mathrm{CH}_{3} \mathrm{O} \cdot \mathrm{C}_{6} \mathrm{H}_{4}$ & $\mathrm{C}_{7} \mathrm{H}_{7} \mathrm{ClHgO}$ & 58.45 & 58.30 & $213-235$ \\
\hline 7 & $p-\mathrm{CH}_{3} \mathrm{OC}_{6} \mathrm{H}_{4}$ & $\mathrm{C}_{7} \mathrm{H}_{7} \mathrm{ClHgO}$ & 58.45 & 58.60 & $224-280$ \\
\hline 8 & $p-\mathrm{Cl}_{2} \mathrm{C}_{6} \mathrm{H}_{4}$ & $\mathrm{C}_{6} \mathrm{H}_{4} \mathrm{ClHg}$ & 57.71 & 57.85 & $137-190$ \\
\hline 9 & $p$-Br. $\mathrm{C}_{6} \mathrm{H}_{4}$ & $\mathrm{C}_{6} \mathrm{H}_{4} \mathrm{BrClHg}$ & 51.16 & 51.40 & $257-322$ \\
\hline 10 & $p$-COOH. $\mathrm{C}_{6} \mathrm{H}_{4}$ & $\mathrm{C}_{7} \mathrm{H}_{5} \mathrm{ClHgO}_{2}$ & 56.16 & 56.35 & $225-274$ \\
\hline 11 & $p$-OH. $m-\mathrm{NO}_{2} \cdot \mathrm{C}_{6} \mathrm{H}_{3}$ & $\mathrm{C}_{6} \mathrm{H}_{4} \mathrm{ClHgNO}_{3}$ & 53.61 & 53.90 & \\
\hline 12 & $p-\mathrm{NH}_{2} \cdot \mathrm{C}_{6} \mathrm{H}_{4}$ & $\mathrm{C}_{6} \mathrm{H}_{6} \mathrm{ClHgN}$ & 61.13 & 61.35 & \\
\hline
\end{tabular}

* The different organomercuric compounds suffer from thermal stability, so that it is better to determine their thermal behavior from TG and DTA plots instead of measuring the melting point.

the organomercuric compounds $\operatorname{ArHgX}(\mathrm{Ar}=$ phenyl or ortho or para substituted phenyl). They are made by reaction of mercuric acetate with benzene, phenol, benzyl alcohol, anisol, chlorobenzene, bromobenzene, $o$ nitrophenol, and aniline to produce the corresponding substituted mercuric compounds. The resulted acetates are transformed into the corresponding chlorides by the action of saturated solutions of sodium chloride or calcium chloride. The produced chloromercury compounds are subjected to purification by crystallization from hot water or ethanol (cf. Table 1).

The separation of ortho isomer from para one in case of hydroxyphenylmercuric chloride and hydroxyphenylmercuric chlorides is achieved by extraction of the former isomer from the reaction product by hot water, till the product is freed of it. On the other hand the para-isomers are extracted from the residue by hot ethanol. Finally, the two isomers are purified by crystallization from hot water and hot ethanol, respectively.

$p$-Carboxyphenylmercuric chloride is prepared by oxidation of $p$-hydroxymethylphenyl-mercuric chloride by means of potassium permanganate in an alkaline solution. The corresponding acid $\left(\mathrm{p}-\mathrm{COOH} \cdot \mathrm{C}_{6} \mathrm{H}_{4} \cdot \mathrm{HgCl}\right)$ precipitates after addition of hydrochloric acid and is purified by crystallization from hot ethanol.

Before starting the preparation of various arylmercuric dithizonate complexes, we have determined the highest percentage of extraction (100\%) of different complexes into organic solvent $\left(\mathrm{CCl}_{4}\right)$ from perchlorate buffer like solutions taking into consideration that the arylmercuric compounds ( $\mathrm{ArHgCl}$ ) react with dithizone $\left(\mathrm{H}_{2} \mathrm{Dz}\right)$ forming $1: 1$ complexes with the molecular for- mula (ArHgHDz). Optimum pH ranges suitable for complete extraction are given in Table 2.

Preparation of solid arylmercuric dithizonate complexes. Solutions of the organomercuric compounds in carbon tetrachloride are shaken with 5\% excess than the stoichiometric amount of dithizone in the same solvent in presence of perchloric acid/sodium perchlorate buffer like solutions

Table 2. pH ranges for complete extraction of complexes form $1 \mathrm{M}$ perchlorate solutions.

\begin{tabular}{ccc}
\hline No & $\mathrm{Ar}$ & $\begin{array}{c}\mathrm{pH} \text { range for complete } \\
\text { extraction of complexes }\end{array}$ \\
\hline 1 & $\mathrm{C}_{6} \mathrm{H}_{5}$ & $1.2-8.2$ \\
2 & $o$-OH. ${ }_{6} \mathrm{H}_{4}$ & $0.6-9.2$ \\
3 & $p$-OH. ${ }_{6} \mathrm{H}_{4}$ & $1.7-9.3$ \\
4 & $o-\mathrm{CH}_{2} \mathrm{OH} \cdot \mathrm{C}_{6} \mathrm{H}_{4}$ & $0.0-9.5$ \\
5 & $p-\mathrm{CH}_{2} \mathrm{OH} \cdot \mathrm{C}_{6} \mathrm{H}_{4}$ & $0.0-9.6$ \\
6 & $o-\mathrm{CH}_{3} \mathrm{O} \cdot \mathrm{C}_{6} \mathrm{H}_{4}$ & $0.0-9.2$ \\
7 & $p-\mathrm{CH}_{3} \mathrm{O} \cdot \mathrm{C}_{6} \mathrm{H}_{4}$ & $0.0-9.1$ \\
8 & $p-\mathrm{Cl}_{2} \mathrm{C}_{6} \mathrm{H}_{4}$ & $0.0-11.2$ \\
9 & $o-\mathrm{BrC}_{6} \mathrm{H}_{4}$ & $0.0-9.8$ \\
10 & $p-\mathrm{COOHC}_{6} \mathrm{H}_{4}$ & $0.0-6.8$ \\
11 & $p-\mathrm{OH} \cdot m-\mathrm{NO}_{2} \cdot \mathrm{C}_{6} \mathrm{H}_{3}$ & $0.0-9.6$ \\
12 & $p-\mathrm{NH}_{2} \mathrm{C}_{6} \mathrm{H}_{4}$ & $4.0-8.8$ \\
\hline
\end{tabular}


(1.0 molar) for 15 minutes. The bright red organic phases are washed with water, aqueous ammonia $(\mathrm{pH}=$ 9) and finally with water again to remove the excess amounts of dithizone.

The organic layer is separated, dried over anhydrous magnesium sulfate and evaporated till dryness at room temperature. That there is no absorption at $620 \mathrm{~nm}$ for solutions of all complexes in carbon tetrachloride $(\mathrm{E}<0.0001)$ means that there is no contamination of dithizone with the complexes, and reflected the very high purity of complexes. In the case of preparation and/or purification of $\left(\mathrm{p}-\mathrm{COOH}-\mathrm{C}_{6} \mathrm{H}_{4}\right) \mathrm{Hg}(\mathrm{HDz})$ the use of buffer solutions with $\mathrm{pH}>9$ led to a sharp decrease in the yield of the produced complex. This phenomenon may be attributed to the formation of water soluble sodium salt.

\section{Chemical analysis of starting organomercuricals and complexes.}

- Determination of mercury (\%) in the arylmercuric compounds and their dithizone complexes

The starting organomercurical (or the dithizone complex) is wet-ashed by boiling in a mixture of $70 \% \mathrm{HClO}_{4}$ and nitric acid under reflux until the solution is free from organic materials. The mercury content is then determined spectrophotometrically by dithizone as a complexing agent with the aid of the construction curve.

- Determination of halogens in the organomercuric compounds and their dithizone complexes

The substance is decomposed with sodium peroxide in a fusion bomb. The product is dissolved in a diluted nitric avid (ca. $0.1 \mathrm{~N})$ followed by filtration. The mercuric species in the filtrate is removed from the solution by dithizone extraction before determination of halo- gens. The chlorine was determined volumetrically by using of mercury diphenylcarbazone and bromophenol blue as indicators. On the other hand the determination of chloride and bromide ions are carried out, simultaneously by titration their solutions with sulfuric acid after neutralisation with mercuric oxycyanide in presence of a mixture composed of methyl red and methylene blue as indicator.

Thermal analysis. The thermal analysis (TG and DTG) of different organomercuricals were carried out using a simultaneous thermoanalyzer (Netzsch-Gerätebau (Germany) STA 409, Type 6.223) with a different scanning colorimeter cell. The rate of heating was $10{ }^{\circ} \mathrm{C} \mathrm{min}-1$. The thermal analysis of the complexes was not carried out till now. Analytical and thermal data are collected in Table 3.

2.2. SPECTROSCOPIC MEASUREMENTS The spectra of the arylmercuric dithizonate complexes were recorded on a Cary 4 UV-VIS spectrophotometer. The excited photosteady state was established after about $30 \mathrm{~s}$ of irradiation with a tungsten lamp, where infrared radiation was removed through filtering with $5 \mathrm{~cm}$ of water in a glass cell. In solution the longest thermal return times have been observed with $\mathrm{CCl}_{4}$ and photochromism was found as a reversible photoinduced change from the ground state A to the metastable excited state $\mathbf{A}^{*}$ followed by thermal return:

$$
\mathbf{A} \underset{k}{\stackrel{\lambda}{\gtrless}} \mathbf{A}^{*}
$$

Low-temperature measurements have been performed by using a helium transfer cryostat and $\mathrm{KBr}$ pellet technique with finely ground powders.

Table 3. Characterization of arylmercuric dithizonate complexes (ArHgHDz.)

\begin{tabular}{|c|c|c|c|c|c|}
\hline No & $\mathrm{Ar}$ & Empirical formula & $\begin{array}{c}\text { Analysis } \\
\text { Calc. }\end{array}$ & $\begin{array}{l}(\mathrm{Hg} \%) \\
\text { Found }\end{array}$ & $\begin{array}{c}\text { Thermal } \\
\text { Decomposition }\end{array}$ \\
\hline 1 & $\mathrm{C}_{6} \mathrm{H}_{5}$ & $\mathrm{C}_{19} \mathrm{H}_{16} \mathrm{HgN}_{4} \mathrm{~S}$ & 37.63 & 37.90 & 533 \\
\hline 2 & $o-\mathrm{OH} . \mathrm{C}_{6} \mathrm{H}_{4}$ & $\mathrm{C}_{19} \mathrm{H}_{16} \mathrm{HgN}_{4} \mathrm{OS}$ & 36.54 & 36.20 & 549 \\
\hline 3 & $p$-OH. ${ }_{6} \mathrm{H}_{4}$ & $\mathrm{C}_{19} \mathrm{H}_{16} \mathrm{HgN}_{4} \mathrm{OS}$ & 36.54 & 36.02 & 549 \\
\hline 4 & $o-\mathrm{CH}_{2} \mathrm{OH} \cdot \mathrm{C}_{6} \mathrm{H}_{4}$ & $\mathrm{C}_{20} \mathrm{H}_{18} \mathrm{HgN}_{4} \mathrm{OS}$ & 35.63 & 35.92 & 563 \\
\hline 5 & $p-\mathrm{CH}_{2} \mathrm{OH} \cdot \mathrm{C}_{6} \mathrm{H}_{4}$ & $\mathrm{C}_{20} \mathrm{H}_{18} \mathrm{HgN}_{4} \mathrm{OS}$ & 35.63 & 35.63 & 563 \\
\hline 6 & $o-\mathrm{CH}_{3} \mathrm{O} \cdot \mathrm{C}_{6} \mathrm{H}_{4}$ & $\mathrm{C}_{20} \mathrm{H}_{18} \mathrm{HgN}_{4} \mathrm{OS}$ & 35.63 & 34.98 & 563 \\
\hline 7 & $p-\mathrm{CH}_{3} \mathrm{O} \cdot \mathrm{C}_{6} \mathrm{H}_{4}$ & $\mathrm{C}_{20} \mathrm{H}_{18} \mathrm{HgN}_{4} \mathrm{OS}$ & 35.63 & 35.87 & 563 \\
\hline 8 & $p-\mathrm{Cl} . \mathrm{C}_{6} \mathrm{H}_{4}$ & $\mathrm{C}_{19} \mathrm{H}_{15} \mathrm{ClHgN}_{4} \mathrm{~S}$ & 35.35 & 35.80 & 567 \\
\hline 9 & $p$-Br. $\mathrm{C}_{6} \mathrm{H}_{4}$ & $\mathrm{C}_{19} \mathrm{H}_{15} \mathrm{BrHgN}_{4} \mathrm{~S}$ & 32.78 & 32.50 & 612 \\
\hline 10 & $p$-СOOH. ${ }_{6} \mathrm{H}_{4}$ & $\mathrm{C}_{20} \mathrm{H}_{16} \mathrm{HgN}_{4} \mathrm{O}_{2} \mathrm{~S}$ & 34.76 & 35.01 & 577 \\
\hline 11 & $p$-OH. $m-\mathrm{NO}_{2} \cdot \mathrm{C}_{6} \mathrm{H}_{3}$ & $\mathrm{C}_{19} \mathrm{H}_{15} \mathrm{HgN}_{5} \mathrm{O}_{3} \mathrm{~S}$ & 33.71 & 34.02 & 595 \\
\hline 12 & $p-\mathrm{NH}_{2} \cdot \mathrm{C}_{6} \mathrm{H}_{4}$ & $\mathrm{C}_{19} \mathrm{H}_{17} \mathrm{HgN}_{5} \mathrm{~S}$ & 33.60 & 33.89 & 548 \\
\hline
\end{tabular}


<smiles>C=CC1=NN(c2ccccc2)NCS1</smiles>

A: orange form<smiles>c1ccc(-c2nn3cc2s[se]n3-c2ccccc2)cc1</smiles>

$\mathrm{A}^{*}$ : blue form
Figure 1. Dithizone coordination in the ground (left) and excited state (right) according to Meriwether's proposal [4]

\section{METHOD OF CALCULATION}

All calculations were carried out with complete geometry optimization. The geometric data were obtained from idealized planar geometries and subsequent PM3 calculations which were performed with the HyperChem 5.1 packet program for Windows NT [11]. The implemented unrestricted Hartree Fock SCF method was used and the gradient method of Polak-Ribiere. Vertical electronic transitions were calculated within the restricted Hartree Fock method using configuration interaction $(\mathrm{CI})$. The $\mathrm{CI}$ wavefunctions are given by linear combinations of single Slater determinants which are generated by taking one electron of one of the highest (e.g. 15) occupied orbitals and placing that electron into one of the lowest (e.g. 15) unoccupied orbitals of the ground state (i.e. CIS 15,15).

We only used the PM3 method because it has been found earlier $[4,6]$ to describe the geometric properties of dithizone and of mercury bisdithizonate significantly better than other semiempirical methods available (MINDO, MNDO, AM1 or ZINDO).

\section{RESULTS AND DISCUSSION}

A typical UV/VIS absorption spectrum for arylmercuric(II) dithizonates is depicted in Figure 2 showing band patterns obtained for the chlorophenyl derivate as solid and in solution. The ground state is characterized by a strong and broad band around $480 \mathrm{~nm}$ giving rise to the brownish or orange color of powders or solutions (e.g. acetonitrile, THF, $\mathrm{CHCl}_{3}, \mathrm{CCl}_{4}$ ), respectively. Further bands of lower intensity appear at shorter wavelengths which may be covered by absorptions of the respective solvent. A weak solvatochromism is present inducing band shifts which are less than $10 \mathrm{~nm}$. Transitions located in the UV are best observed with the $\mathrm{KBr}$ pellet technique at low-temperatures although some intensity at shorter wavelengths is then due to light scattering. The spectrum measured at $\mathrm{T}=8 \mathrm{~K}$ exhibits a pronounced finestructure and we note a splitting of the first band into to components separated by about $30 \mathrm{~nm}$.

In order to get definitive assignments we have calculated transitions energies and intensities with the PM3 method using configuration interaction within single excitations between 20 occupied and 20 unoccupied orbitals (RHF:CIS 20,20).

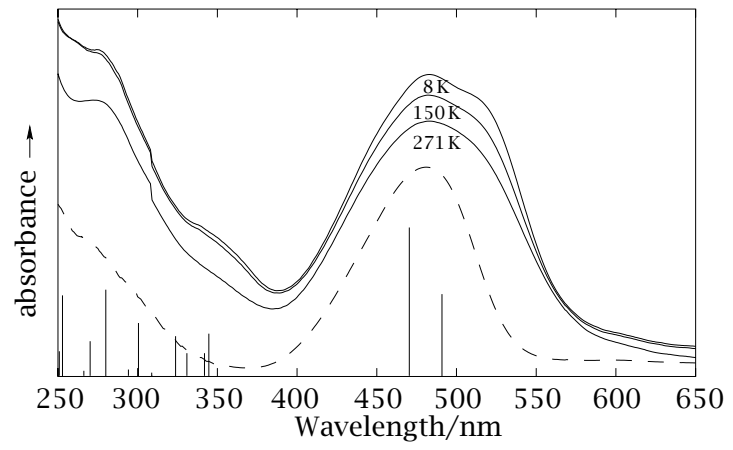

Figure 2. Low-temperature absorption spectra of solid $(\mathrm{Cl}-\mathrm{ph}) \mathrm{Hg}(\mathrm{HDZ})$. the dashed line shows the $\mathrm{CCl}_{4}$ solution spectrum, bars indicate calculated spin-allowed electronic transitions(see text).

The result is given with the bars in Figure 2, showing the experimental band pattern to be well reproduced if reasonable half band widths are assumed. We will describe here the results of our semiempiric investigations only for the chlorophenyl complex as a representative example. According to such calculations the transitions in the visible part of the absorption spectrum located around $490 \mathrm{~nm}$ and $470 \mathrm{~nm}$ arises from an electron being transferred from occupied orbitals No. 60 and 63 into the unoccupied orbitals No. 64 and 65, respectively. Therefore electrons located mainly within the $\mathrm{S}-\mathrm{C}-\mathrm{N}-\mathrm{N}$ unit are transferred towards mercury and the opposite phenyl group (s-type) or occupy a more extended $\pi$-MO spread over the whole dithizone ligand (see Figure 3).
60

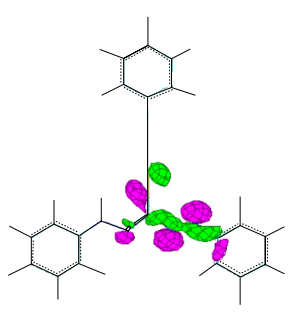

64

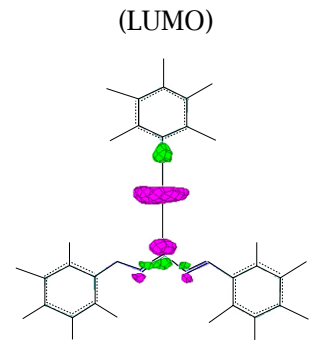

(Cl-Ph)-Hg-(HDZ)
63 (HOMO)

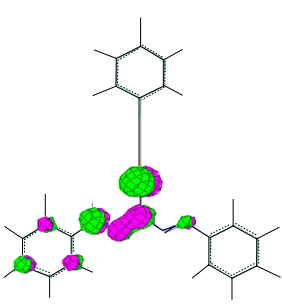

65

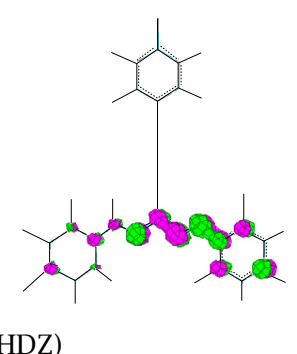

Figure 3. MO's involved in the long wavelength singletsinglet transitions in $(\mathrm{Cl}-\mathrm{Ph}) \mathrm{Hg}(\mathrm{HDz})$ as calculated with the PM3 method (see text).

The calculated difference in the orbital energies is about $30000 \mathrm{~cm}^{-1}$, however, the significant larger expansion of orbitals 64 and 65 reduces interelectronic repulsion leading to transition energies at smaller 
wavenumbers. Transitions from the HOMO (63) towards higher unoccupied orbitals (No. 68, 72, 71) are responsible for some intense transitions at higher energies (calculated at $324 \mathrm{~nm}, 280 \mathrm{~nm}$, and $251 \mathrm{~nm}$, respectively).
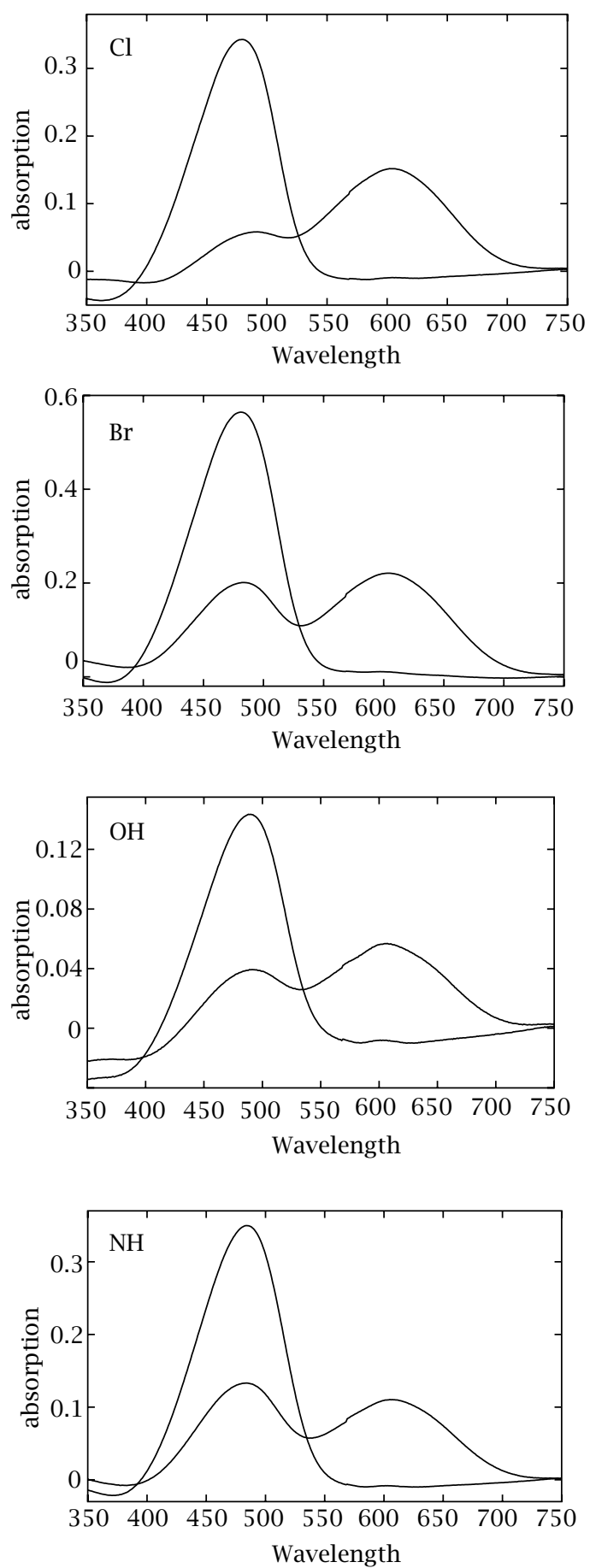

Figure 4. Visible absorption spectra of $(X-P h) H g(H D z), X=C l$, $\mathrm{Br}, \mathrm{NH} 2 \mathrm{OH}$, before (bold lines) and $20 \mathrm{~s}$ after irradiation (30s) with a tungsten lamp.

Photochromism. The phenomenon of photochromism is well-known [12] and was discovered for mercury bisdithizonate fifty years ago (Reference [1, p.36]). Pho- tochromism is observable for all of the arylmercuric(II) dithizonates described here. It appears as orange - blue photoisomerism with remarkable long lifetimes in the range of seconds to minutes depending on the solvent or the embedding material (matrix), respectively. The metastable blue form $\mathrm{A}^{*}$ absorbs light at longer wavelengths around $600-650 \mathrm{~nm}$ and produces blue solutions when irradiated with a tungsten lamp for 30-60 s. The typical band patterns of unexposed and excited complexes dissolved in $\mathrm{CCl}_{4}$. are depicted in Figure 4.

In order to derive kinetic data we have performed time dependent measurements after irradiation of dissolved and film-embedded complexes. A typical series of spectral runs for successive degrees of dark return is depicted in Figure 5 for the complex $(\mathrm{p}-\mathrm{BrPh}) \mathrm{Hg}(\mathrm{HDz})$. Isosbestic points are well maintained, indicating that no secondary photolysis or reaction products appear. The molar extinction of the ground state $\mathbf{A}$ is about $17 \cdot 10^{3} \mathrm{M}^{-1} \mathrm{~cm}^{-1}$ and the respective value for the photoactivated metastable blue form $\mathbf{A}^{*}$ is evaluated from the kinetic study to be $9 \cdot 10^{3} \mathrm{M}^{-1} \mathrm{~cm}^{-1}$.

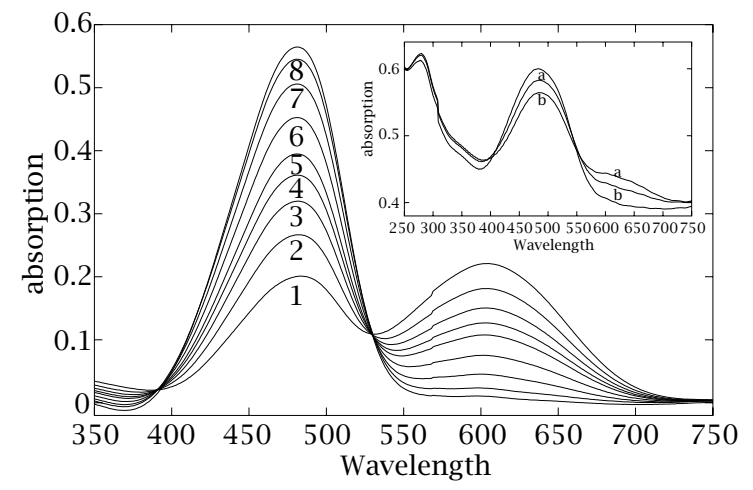

Figure 5. Spectral changes on dark return for $(\mathrm{Cl}-\mathrm{Ph}) \mathrm{Hg}(\mathrm{HDz})$ recorded at intervals of $20 \mathrm{~s}(1-5)$, and at $160 \mathrm{~s}$ (6),380 s (7), $500 \mathrm{~s}$ (8); the bold line shows the spectrum of the relaxed system. Film spectra are given in the inset, where $a$ and $b$ label return times of 5 min and 60 min, respectively.

The inset shows the time evolution for this complex as a film obtained by slow evaporation from $\mathrm{CCl}_{4}$ solution upon a sapphire plate. It is noted that the return time is delayed by a factor of about 100 , in particular when the samples are cooled below $100 \mathrm{~K}$. Further investigations in this field will be subject of our future work.

Up to now there are still no x-ray data available for the excited state geometries of the metastable photochromic dithizone complexes. On the other hand, there is some evidence that the postulate of Meriwether et al. given for the primary mercury(II) bisdithizonate complex (see above) properly describes also the geometric features of the metastable state $\mathbf{A}^{*}$ in metal complexes with only one dithizone ligand [13]. Therefore we used the PM3 optimized geometries of the respective ground state and obtained a conceivable structure for the metastable state by subsequent $180^{\circ}$ rotation around the $\mathrm{C}=\mathrm{N}$ bond axis (Figure 6). Geometry 
optimization raises the planarity slightly, however, interatomic distances and bond angles are not altered significantly. Likewise, calculations of the typical absorption located around $610 \mathrm{~nm}$ were not much effected by taking into account the slightly different geometries. It turned out that the respective MO's in the HOMOLUMO region are more diffuse and located closer to the sulfur and mercury atoms. This leads to smaller gaps for the orbital energey differences and subsequently to smaller transition energies. We have treated this field in more detail for the zinc and mercury bisdithizonate complexes, where x-ray data are available at least for the ground state geometries [14].

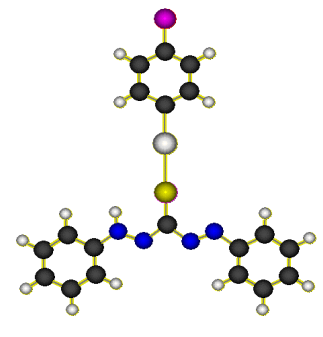

A: orange form

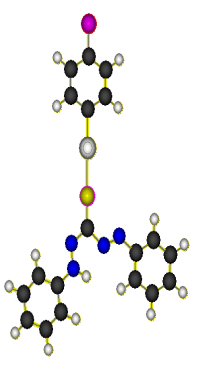

$\mathrm{A}^{*}$ : blue form
Figure 6. Assumed geometries for arylmercuric dithizonate complexes.

\section{CONCLUSION}

Arylmercuric dithizone complexes can be synthesized in pure fractions when specific handlings are obeyed. All complexes exhibit pronounced photochromism showing slow thermal return times in $\mathrm{CCl}_{4}$ solution or even longer when embedded into films. An isomerisation within the dithizone ligand followed by electronic rearrangement and proton transfer is responsible for the activated metastable complex. This mechanism is established also for the mercury(II) bisdithizonate complex. The absorption band maxima of the ground and metastable excited states are well re- produced by PM3 calculations.

We conclude that to avoid the limitations of ab initio methods it is valuable to use reliable semiempirical methods in order to understand the behavior of dithizone complexes and, moreover, to make predictions about new compounds within that family of photochromic materials.

\section{ACKNOWLEDGEMENTS}

We gratefully acknowledge support from the Deutsche Forschungsgemeinschaft (DFG), Bonn, and from the Gesellschaft für Technische Zusammenarbeit (GTZ), Eschborn, Germany.

\section{REFERENCES}

[1] H. M. N. H. Irving, Dithizone, The Chemical Society, Burlington House, London, 1977.

[2] A. T. Hutton, Polyhedron 6 (1987), 13.

[3] J. Fabian, G. Röbisch, and R. Nöske, Dyes and Pigments 8 (1987), 165.

[4] V. Schmid, Diplomarbeit, 1997, Düsseldorf.

[5] T. Schönherr, V. Schmid, and U. Rosellen, to be published.

[6] S. Grimme, University of Bonn, private communication on DFT results.

[7] T. Schönherr and V. Schmid, Ab initio and semiempiric calculations on dithizone and related complexes, 12th ISPPCC, 1997, Vermont, p. 76.

[8] T. Schönherr, to be published.

[9] L. S. Meriwether, E. C. Breitner, and N. B. Colthup, J. Amer. Chem. Soc. 87 (1965), 4448.

[10] H. M. N. H. Irving and A.M. Kiwan, Analy. Chim. Acta 45 (1969), 271.

[11] Internet address: "http://www.hyper.com/ products/default.htm".

[12] H. Dürr (ed.), Photochromism: Molecules and Systems, Elsevier, Amsterdam, 1990.

[13] A. T. Hutton and H. M. N. H. Irving, J. Chem. Soc. Dalton Trans. (1982), 2299.

[14] M. Laing, J. Chem. Soc. Perkin Trans. II (1977), 1248. 


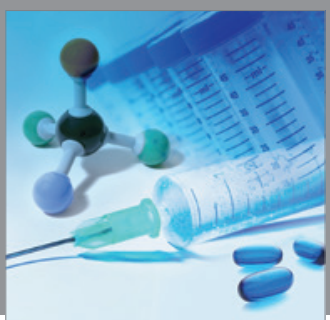

International Journal of

Medicinal Chemistry

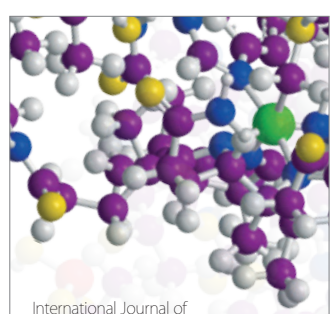

Carbohydrate Chemistry

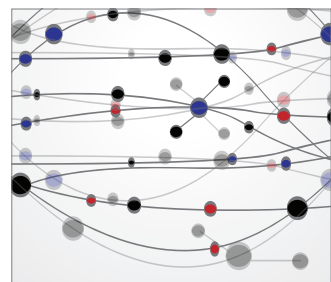

The Scientific World Journal
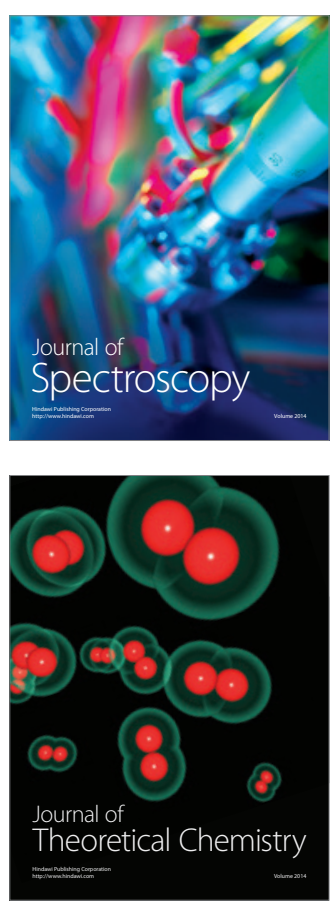
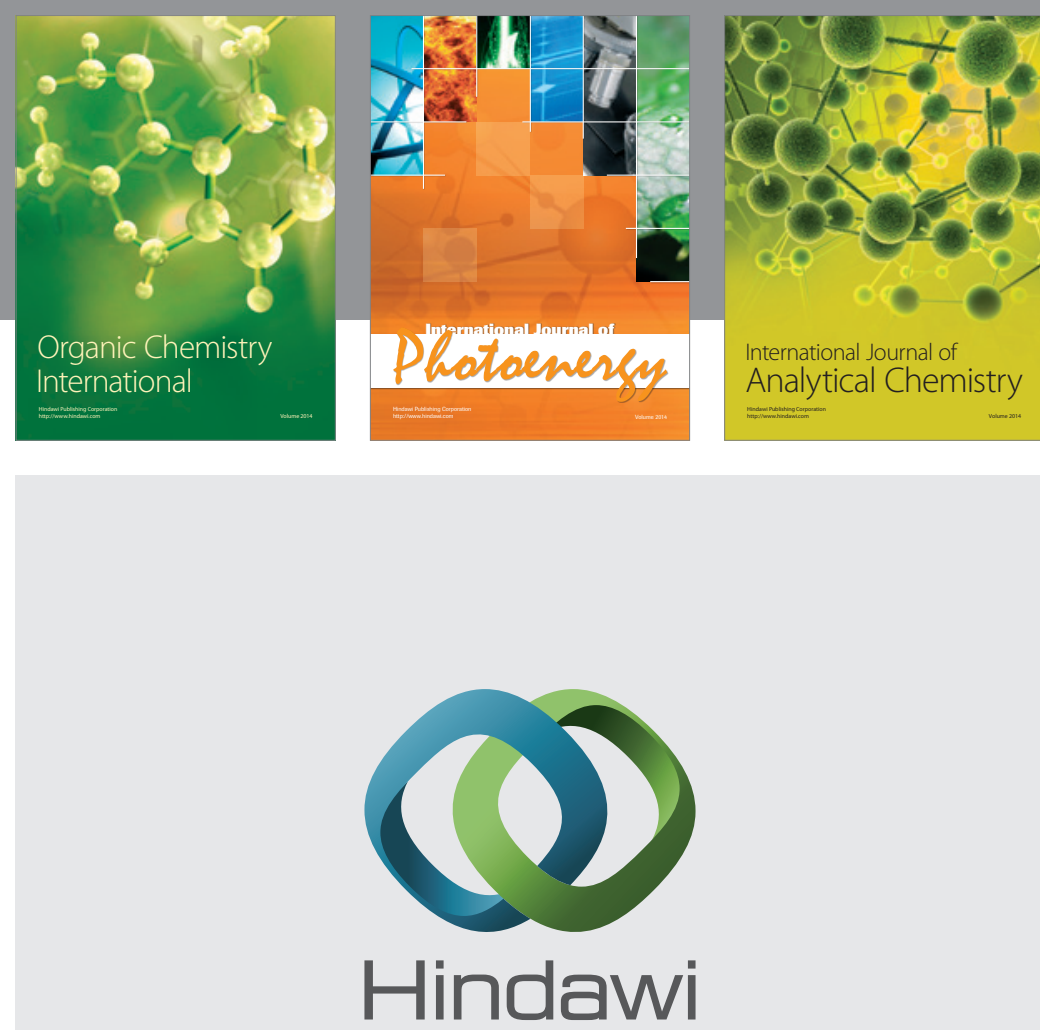

Submit your manuscripts at

http://www.hindawi.com
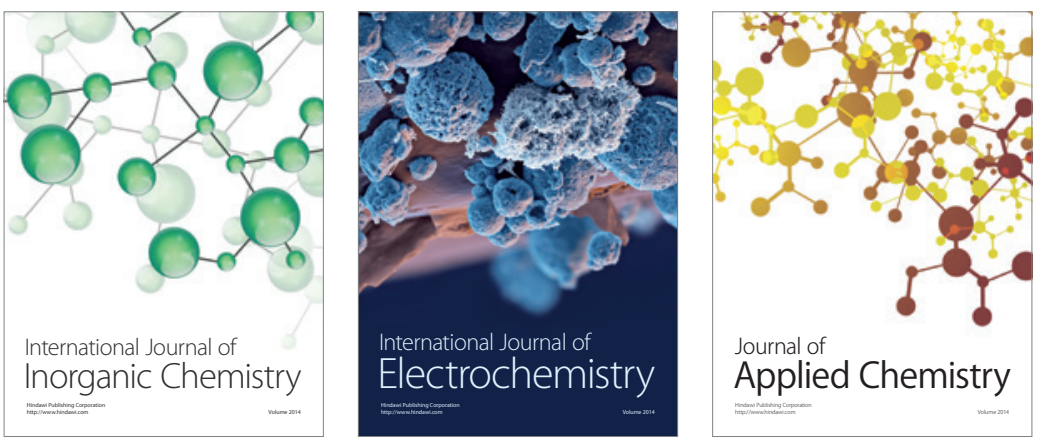

Journal of

Applied Chemistry
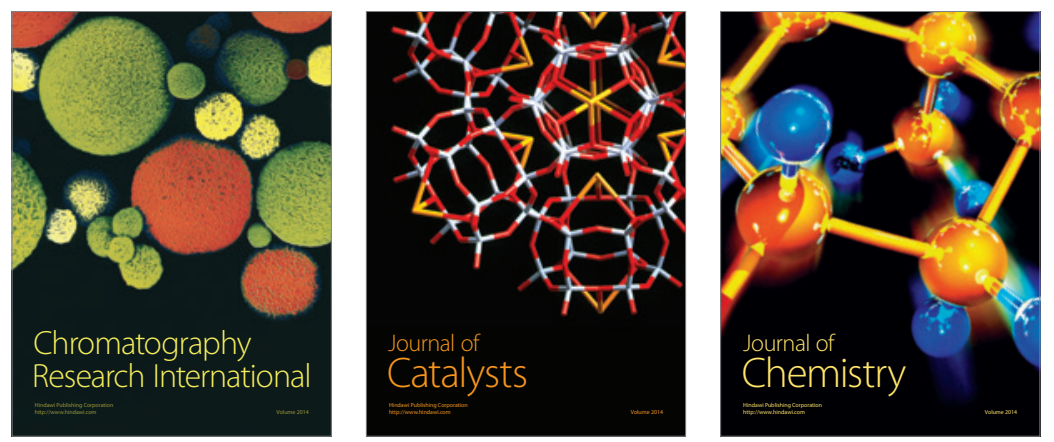
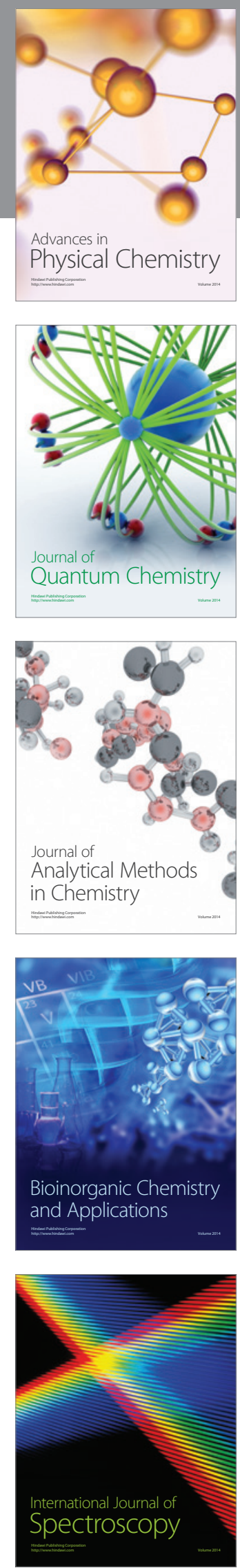